\title{
Hedge funds and higher moment portfolio selection
}

\author{
Greg Bergh and Paul van Rensburg* \\ *School of Management Studies, University of Cape Town, Private Bag, Rondebosch 7701, \\ South Africa. \\ Tel: + 2721 6502481,Fax: + 2721 6897570; E-mail: pvanrens@commerce.uct.ac.za \\ Received (in revised form): 22nd November, 2007
}

Greg Bergh is a director and fund manager with Praesidium Capital Management, a specialist hedge fund firm in South Africa.

Paul van Rensburg is the Frank Robb Professor of Finance at the University of Cape Town and Principal of Salient Quantitative Asset Management.

\section{Practical applications}

The paper aids sophisticated investors and analysts in understanding the implications of the higher moment characteristics of hedge fund return distributions. This is useful in the application of portfolio construction of fund of hedge funds as well as in determining the appropriate allocation to hedge funds within a traditional portfolio of equities and bonds. The paper also highlights less apparent risks and advantages in particular hedge fund strategies.

\begin{abstract}
Notwithstanding the central limit theorem, the returns of several hedge fund indices are found to exhibit distributional characteristics inconsistent with normality. Using world hedge fund index and asset class data from 1994 to 2004, this study empirically compares the results of the Markowitz mean-variance optimisation technique with a higher moment methodology recently proposed by Davies et al. This comparison is conducted both when constructing fundof-hedge-fund portfolios and when determining an appropriate weighting to apply when adding hedge funds to the traditional asset classes of equities, bonds and cash. The descriptive statistics show that, in particular, the hedge fund strategies of Fixed Income Arbitrage and Event-driven Opportunities, despite displaying low volatility, exhibit latent higher moment
\end{abstract}

risk in the form of negative skewness and high kurtosis. These two higher moments collectively suggest an increase in the probability of extreme adverse returns to the investor that is not revealed in traditional meanvariance analysis. Confirming the findings of Amin and Kat and Lo, Jarque-Bera tests find that only two out of the 14 hedge fund indices used in this study are normal at the 5 per cent level. Applying Markowitz mean-variance portfolio selection to an array of published hedge fund indices produces fund-of-fund portfolios with higher ex post returns but naive exposure to undesirable higher moment risks. When the higher moments of hedge fund index return distribution are accounted for in the portfolio optimisation algorithm, the resultant portfolios have improved diversification and higher moment statistics. This study confirms the findings of Davies et al. and Feldman et al.
Journal of Derivatives \& Hedge Funds, Vol. 14 No. 2, 2008, pp. 102-126 (C) 2008 Palgrave Macmillan Ltd 1753-9641 
that Global Macro and Equity Market Neutral strategies are crucial constituents in a fund-of-hedge-funds portfolio. When constructing multi-asset class portfolios that include an allocation to hedge funds, the results show that meanvariance optimisation significantly over-allocates to the hedge fund class in comparison to when skewness and kurtosis are also taken into account. The higher moment-optimised portfolios all outperform the mean-variance comparatives when evaluated on an Omega function basis. Journal of Derivatives \& Hedge Funds (2008) 14, 102-126. doi:10.1057/jdhf.2008.14

Keywords: skewness; kurtosis; hedge funds; mean-variance; portfolio selection

\section{INTRODUCTION}

Two key tasks faced by industry practitioners are that of asset allocation and that of strategy allocation within the hedge fund universe. It is well documented (see Cvitani'c et al., ${ }^{1}$ Agarwal and Naik, ${ }^{2}$ Amenc and Martellini ${ }^{3}$ and Amin and $\mathrm{Kat}^{4}$ ) that hedge funds are marked by their heterogeneity and unusual statistical properties. This makes the use of conventional methods of portfolio construction subject to question and necessitates the investigation of a more sophisticated approach to inform the construction of appropriate and efficient portfolios. This paper compares and evaluates the results of two related optimisation procedures. First, the classic meanvariance portfolio optimisation of Markowitz ${ }^{5}$ and secondly, a recent approach introduced by Davies et al. ${ }^{6}$ utilising Polynomial Goal Programming (PGP) to optimise portfolios return distributions for higher moments to include mean, variance, skewness and kurtosis for a given set of investor preferences. This comparison will be presented in the context of both a fund-ofhedge-fund strategy allocation as well as the asset allocation problem of what proportion to allocate to hedge funds in a balanced portfolio.

The remainder of the paper is organised as follows: The second section presents a brief theoretical overview of the relevance of skewness and kurtosis, and performance appraisal measures that take these features into account. The third section provides a review of the prior literature relating to portfolio construction involving hedge funds, both in terms of an asset allocation decision and when constructing a fund-of-hedge-funds portfolio. Thereafter, the data, descriptive statistics and methodology are presented. The analysis is applied to the two problems of (i) fundof-hedge-fund strategy allocation and (ii) the asset allocation decision with hedge funds. Finally, the eighth section concludes.

\section{THE HIGHER MOMENTS OF A PROBABILITY DISTRIBUTION}

A normal distribution is fully described by its mean and variance and it is widely used, due to its mathematical tractability. The normal distribution has its theoretical motivation in the Central Limit Theorem, which states that the average distribution of an increasing number of independent variables approaches a normality if certain conditions are fulfilled. These conditions can be summarised as follows:

(1) The mean and standard deviations or the processes generating the returns should be stationary over time.

(2) The processes generating the returns should be independent of each other rather than a function of general systematic factors. 
Johnson et al. ${ }^{7}$ comment: 'It is fairly obvious that neither of these conditions is strictly true for hedge funds and it is in part for this reason that the "fat-tails" appear in the distributions of hedge fund strategy returns. For example, systematic trendfollowers depend on the existence of trends in various financial markets so that the returns of managers operating this strategy will tend to exhibit a high degree of interdependence and notable time structure'.

In terms of quantifying the nature of nonnormality, skewness is a commonly used measure of symmetry (or more precisely, a lack of symmetry):

$$
\text { Skewness }=\frac{n}{(n-1)(n-2)} \sum\left(\frac{x_{j}-\bar{x}}{\sigma}\right)^{3}
$$

where $\bar{x}$ is the mean, $\sigma$ is the standard deviation and $n$ is the number of data points in the sample. The skewness of a normal distribution is zero. From a portfolio perspective, investors prefer portfolios with higher (right-skewed) skewed distributions.

Kurtosis is a measure of how the relative peakedness or flatness of a distribution compares with the normal distribution, with higher values implying fatter tails. The standard formula for calculating excess portfolio kurtosis is:

$$
\begin{aligned}
\text { Kurtosis }= & \left\{\frac{n(n+1)}{(n-1)(n-2)(n-3)} \sum\left(\frac{x_{j}-\bar{x}}{\sigma}\right)^{4}\right\} \\
& -\frac{3(n-1)^{2}}{(n-2)(n-3)}
\end{aligned}
$$

where $\bar{x}$ is the mean, $\sigma$ is the standard deviation and $n$ is the number of data points in the sample. The kurtosis value of a normal distribution is three.

The relevance of non-normality in returns from an investors' perspective is that his utility function is influenced by the values of these higher moments. As stated by Athayde and Flores: 'In general, investors will prefer high values for odd moments and low ones for even moments. The former can be seen as a way to decrease extreme values on the side of losses and increase them on the gains. The latter can be justified by the fact that even moments measure dispersion, and therefore volatility; something undesirable because it increases the uncertainty of returns'. In other words, investors would like to maximise the first and third moments (mean and skewness) and minimise the second and fourth (variance and kurtosis).

In the ensuing analysis, two risk measures that take account of the non-normality of returns are applied. The Sortino Ratio was introduced by Sortino and Price ${ }^{9}$ and is essentially a derivative of the Sharpe Ratio. The Sortino Ratio substitutes standard deviation for the downside deviation (or semi-standard deviation) statistic. This means that the measure does not penalise upside volatility. The downside deviation can be measured from any given point but is usually measured either below the risk-free rate or zero. In this study, the Sortino Ratio is defined as the excess portfolio return beyond the risk-free rate per unit of downside volatility as measured by the semi-standard deviation.

$$
\text { Sortino Ratio }=\frac{E\left(r_{p}\right)-r_{f}}{\sigma_{d p}}
$$

where $E\left(r_{p}\right)$ denotes the expected return of the portfolio, $r_{f}$ the risk-free rate and $\sigma_{d p}$ the semi-standard deviation of the portfolio return series. And the semi-standard deviation is: $\sigma_{d p}=(1 / n-1) \Sigma\left(E_{d r}-r_{f}\right)^{2}$, where $E_{d r}$ denotes returns below the risk-free rate $r_{f}$. 
The Omega function was developed by Shadwick and Keating ${ }^{10}$ and incorporates all the higher moments into a performance evaluation. The function also takes into consideration a 'threshold level' above which an investor would be satisfied with the absolute return and vice versa. The objective of the authors was to find a 'universal performance measure'. Unlike other performance measures such as Sharpe or Sortino (which only consider the volatility and downside volatility of returns, respectively), the Omega function was designed to take the entire return distribution into account.

The Omega function is defined as follows:

$$
\Omega(r)=\frac{\int_{r}^{b}[1-F(x)] \mathrm{d} x}{\int_{a}^{r} F(x) \mathrm{d} x}
$$

where $x$ is the random one-period return on an investment, $r$ is a threshold selected by the investor and $a$ and $b$ denote the upper and lower bounds of the return distribution, respectively. The Omega ratio is effectively the area of the distribution above the threshold level divided by the area below the threshold level. This is an important measurement tool for portfolios that include hedge funds. From a risk-adjusted perspective, it is critical that performance is assessed in the context of the potential increased probability of large extreme losses in hedge funds. Kazemi et al. ${ }^{11}$ show that for ease of calculation, the Omega function can also be expressed as the ratio of the price of a long European call option on the investment divided by the price of a long European put option, where the strike price is the investor threshold level.

\section{PRIOR RESEARCH}

\section{The allocation to hedge funds in a balanced portfolio}

In a study of the risk and return benefits of traditional portfolios with a hedge fund allocation, Schneeweis et al. ${ }^{12}$ construct portfolios including hedge funds using the Markowitz mean-variance model. The authors use returns series data from hedge fund data provider EACM, the S\&P500 large-cap equity index and the Salomon Brothers Government/ Corporate Bond Index over the period 19901998. They find that under historical market conditions, a portfolio of hedge funds offers improved risk and return characteristics when pooled with traditional stock as well as balanced (multi-asset) portfolios. The authors specifically state that '... the low correlation between stock, bond markets, and a wide variety of alternative investments makes the results (improved risk and return opportunities) for the inclusion of various hedge fund strategies ... consistent across a wide variety of stock and bond portfolios'. Their findings are supportive of the hypothesis that an inclusion of hedge funds in the investment opportunity set enhances the efficient frontier and resultant investor utility. Using this methodology with no allocation constraints often leads to large allocations to hedge funds (ie in excess of 90 per cent).

In a related work, Schneeweis and Georgiev ${ }^{13}$ replace the Salomon Brothers Government/ Corporate Bond Index with the Lehman Brothers Bond Index, and the data cover a longer period, from 1990-2001. They conclude that hedge funds offer the opportunity to reduce portfolio variance and enhance portfolio returns in economic environments in which traditional stock and bond investments offer limited opportunities. They also note that the allocation 
to hedge funds under this mean-variance framework, however, may be '.... affected by the historical high returns achieved by hedge funds in the first half of the 1990's'. Amenc and Martellini ${ }^{3}$ caution that portfolio optimisation procedures are very sensitive to differences in expected returns. They caution that portfolio optimisers typically allocate the largest proportion of capital to the asset class for which the estimation error in the expected returns is the greatest.

The conventional mean-variance approach above is also criticised by numerous other investigations, including Cvitani'c et al., Agarwal and Naik, ${ }^{2}$ Amenc and Martellini ${ }^{3}$ and Amin and Kat. ${ }^{4}$ These studies observe that mean-variance portfolio optimisation makes the key assumption of normal asset return distributions. Lo ${ }^{14}$ states that 'hedge-fund returns are highly non-normal, ie, they are asymmetrically distributed, highly skewed, often multi-modal, and with fat tails that imply many more tail events than the normal distribution would predict'. Research conducted by Amin and $\mathrm{Kat}^{4}$ finds that 'The return distribution of a number of hedge fund indices appears to be highly skewed'. Amin and $\mathrm{Kat}^{4}$ also find that only 14.1 per cent of the individual hedge fund returns are normal, utilising a Jarque-Bera test for normality at the 5 per cent significance level.

Amin and $\mathrm{Kat}^{4}$ conduct a study with the objective of examining the effects of diversification by adding hedge funds to a traditional stock and bond portfolio. More specifically, they study the change in the portfolio return distribution with the hedge fund augmentation. They find similar results to Schneeweis and Georgiev, ${ }^{13}$ and Schneeweis et al. ${ }^{12}$ : that the inclusion of hedge funds significantly improves the portfolios meanvariance characteristics. They also, however, find that portfolios constructed of equities and hedge funds do not combine well into truly low risk portfolios as this lowers the skewness and increases the kurtosis of the portfolio. The authors note that '... in terms of skewness hedge funds and equity do not mix very well. In economic terms, the data suggest that when things go wrong in the stock market, they also tend to go wrong for hedge funds. In a way, this makes sense. A significant drop in stock prices will often be accompanied by a widening of a multitude of spreads, a drop in market liquidity, etc'.

\section{Constructing fund-of-hedge-fund portfolios}

Several recent studies investigate the construction of the optimal fund-of-hedgefunds portfolio. Fund-of-hedge-funds are often seen by investors as an efficient manner to access hedge fund manager capability. Industry data provider Hedge Fund Research (HFR) statistics show that fund-of-hedge-funds currently hold 30 per cent of the estimated $\$ 650$ billion invested in hedge funds globally, as of December 2003.

Amin and $\mathrm{Kat}^{4}$ analyse the performance of baskets of hedge funds ranging in size from 1 to 20 funds. Using 1,721 hedge funds (drawn from the Tremont TASS database) from June 1994 to May 2001, they show that increasing the number of funds can be expected to lead not only to a lower volatility, but also, and less appealingly, to lower skewness and increased correlation with the S\&P500. Most of this change occurs for relatively small portfolios holding less than 15 hedge funds and, thereafter, holding additional funds seems to have little effect on the portfolio's return distribution.

Lhabitant and Learned ${ }^{15}$ investigate the same question using a naïvely diversified 
(equal-weighted) Monte Carlo simulation on a database of 6,985 hedge funds. They find that increasing the number of hedge funds (from 1 to 50 funds) in a portfolio reduces the return distribution symmetry and increases kurtosis. The authors find that most of the diversification benefits are delivered with a small number of hedge funds (5-10 funds).

Feldman et al. ${ }^{16}$ develop a simulation-based optimisation method for the construction of optimal fund-of-hedge-fund portfolios that is based on the skewness and kurtosis of returns. Vector autoregression (VAR) methods are used to model the relations among asset returns. Investor preferences are represented by a group of utility functions that integrate both risk and loss aversion. Results suggest that the returns to Market-Neutral and Global Macro funds have distributional characteristics that make them attractive investment vehicles for risk and loss-averse investors.

Davies et al. ${ }^{17}$ explore the interaction of the higher order co-moments and their impact on portfolio construction. They specifically focus on the higher co-moments between various hedge fund strategies, particularly co-skewness and co-kurtosis, and observe that '... diversification deteriorates skew and improves kurtosis in most strategies. Skewness in all strategies, kurtosis in all but distressed securities and merger arbitrage funds are reduced when moving from the individual fund level to the portfolio level. This implies a tradeoff between variance-skewness-kurtosis in hedge fund portfolios. Thus, mean-variance optimal criteria can lead to sub-optimal portfolios in the presence of skewness and kurtosis'. Davies et al. ${ }^{17}$ draw a similar conclusion as Feldman et al. ${ }^{16}$ that Market-Neutral funds and Global Macro funds have a key role in optimal hedge fund portfolios. In addition, the authors conclude that
Market-Neutral funds are kurtosis reducers while Global Macro funds are skewness enhancing. They find that as more funds are included, portfolio volatility (standard deviation) and skewness fall. Davies et al. ${ }^{17}$ note: 'Risk and skewness reduction both occur at a decreasing rate, with the reduction in portfolio skewness occurring at a much slower speed. Since positive skewness is generally a desirable trait, there is a clear trade-off between skewness and risk'.

This finding concurs with that of Lhabitant and Learned ${ }^{15}$ and is the rationale behind their conclusion to limit the number of funds within a fund-of-hedge-fund portfolio to 5-10 funds. Davies et al. ${ }^{17}$ find that as the number of funds contained in the fund-of-hedge-funds increases, '...portfolio expected skewness depends only on the coskewness between three different funds' and that following the same rationale 'portfolio expected standard deviation depends only on covariance and portfolio expected kurtosis depends only on the cokurtosis between four different funds. The influence from individual fourth central moment, cokurtosis between two different funds and three different funds on expected portfolio kurtosis tends to zero'. Both studies agree that as a number of Event-Driven type strategies are included, the kurtosis of the portfolio will increase (the fund-of-hedgefunds becomes more likely to be affected by a systematic shock, eg LTCM, the failure of a mega-merger, etc).

In a related work, Davies et al. ${ }^{6}$ utilise a PGP technique to construct fund-of-hedge-fund portfolios adjusting for investor preferences with respect to competing objectives in terms of mean, variance, skewness and kurtosis. The findings from this study confirm their earlier work above and provide a useful framework for optimising hedge fund portfolios. It is 
this methodology that is used in this study to investigate optimal allocations to hedge funds within a traditional portfolio, as well as allocation among hedge fund strategies within a fund-of-hedge-funds.

\section{DATA}

The data utilised in this study consist of monthly world hedge fund index data and long-only market index data from January 1994 until the end of June $2004 .{ }^{18}$ Hedge fund index data are provided by CSFB Tremont and the market index data by Morgan Stanley Capital International (MSCI) and Lehman Brothers. The hedge fund data below are organised according to the UBS Warburg classifications (Ineichen) ${ }^{19}$ with corresponding weightings in the Composite index. The Event-Driven category has three sub-indices for which no weightings are available.

CSFB tremont world hedge fund composite 100 per cent

Relative value indices:

CSFB Tremont Hedge fund convertible arbitrage (\%)

CSFB Tremont Hedge fund equity market neutral $(\%)$

CSFB Tremont Hedge fund fixed income arbitrage (\%)

Event-driven indices:

CSFB Tremont Hedge fund event driven (\%)

CSFB Tremont Hedge fund distressed securities

CSFB Tremont Hedge fund event driven multi-strategy

CSFB Tremont Hedge fund risk arbitrage
Opportunistic indices:

CSFB Tremont Hedge fund managed

futures $(\%)$

CSFB Tremont Hedge fund global

macro $(\%)$

CSFB Tremont Hedge fund long/short

equity $(\%)$

CSFB Tremont Hedge fund dedicated

short bias (\%)

CSFB Tremont Hedge fund emerging

markets (\%)

Other:

CSFB Tremont Hedge fund

multi-strategy (\%)

CSFB Tremont is a major provider of hedge fund data and compiled the first asset-weighted hedge fund indices. These hedge fund indices use the TASS database as the source of the individual hedge fund data. TASS is one of the leading providers of individual hedge fund data. The CSFB Tremont indices also have minimum criteria for inclusion into the index: a minimum of US $\$ 10$ million assets under management,

a minimum one-year track record and current audited financial statements. The index is calculated and rebalanced monthly. Funds are reselected on a quarterly basis as necessary. To minimise survivorship bias, funds are not removed from the index until they are fully liquidated or fail to meet the financial reporting requirements.

Liang ${ }^{20}$ finds survivorship bias in hedge fund return data from January 1992 through to December 1996. The author, however, concludes that, on a risk-adjusted basis, the average hedge fund outperformed the average mutual fund and that the outperformance cannot be explained by survivorship bias. Amin and 
$\mathrm{Kat}^{4}$ find that concentrating on surviving funds only will overestimate the mean return on individual hedge funds by approximately 2 per cent and will introduce significant biases in estimates of the standard deviation, skewness and kurtosis. Specifically, they point to: '... significant underestimation of the standard deviation and kurtosis as well as overestimation of the skewness of individual hedge fund returns'. Studies relating to survivorship bias with respect to hedge fund returns have not been extended to that of hedge fund indices as used in this study. Ineichen ${ }^{19}$ addresses this issue as follows: 'For hedge funds, it is unclear if survivorship bias inflates returns of hedge fund indices. Poor, as well as stellar performing hedge funds, exit the database. Poor hedge funds exit because of poor performance. Stellar hedge funds can close to new partners and, as a result of good performance, stop reporting returns to the data vendor. Hedge funds report their performance on a voluntary basis. This self-selection bias may partially offset the survivorship bias caused by the disappearance of poorly performing funds'.

Survivorship bias in hedge fund index data is beyond the scope of this paper. And as there is a lack of any conclusive research on the matter, as well as efforts by CSFB Tremont to minimise the impact of survivorship bias in their index data, all empirical research will use the published data in its original format.

The MSCI World Index is a free floatadjusted market capitalisation index that measures global developed market equity performance. As of December 2003, the MSCI World Index consisted of the following 23 developed market country indices: Australia, Austria, Belgium, Canada, Denmark, Finland, France, Germany, Greece, Hong Kong, Ireland, Italy, Japan, the Netherlands, New Zealand, Norway, Portugal, Singapore, Spain, Sweden,
Switzerland, the United Kingdom and the United States.

The MSCI World Sovereign Bond Index is a market capitalisation index that is designed to measure global developed market fixed interest performance. Over 50 per cent of the index consists of debt originating from Japan (28.7 per cent), the United States (19.5 per cent) and Germany (9.8 per cent). Cash returns are proxied using the Lehman Brothers Cash Composite. Long-only index data are sourced from the Bloomberg database. All indices in this study are denominated in US dollars.

\section{DESCRIPTIVE STATISTICS}

As this paper focuses on hedge fund portfolio optimisation incorporating four moments, all the data series are analysed according to moments and Jarque-Bera test statistic and can be found in Table 1 .

It can be seen from the statistics in Table 1 that most hedge fund strategies (with the exception of the Dedicated Short-Bias strategy) have a higher monthly mean return than either global equities or bonds over the sample period. The top three performing hedge fund strategies in absolute terms over the period are Global Macro, Distressed Securities and Long/Short Equity. The worst performing hedge fund strategy is that of Dedicated Short-Bias. All of these strategies can be categorised as opportunistic under the UBS Warburg classification discussed earlier in the fourth section.

From a volatility perspective, the least volatile hedge fund strategy is that of Equity Market Neutral and the only series less volatile is that of US cash, as displayed in Table 1. This is quite intuitive given that these portfolios are largely 
Table 1: Descriptive statistics including the first four moments and the Jarque-Bera test statistic

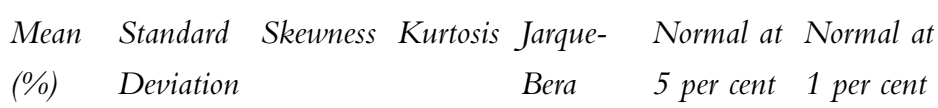

$(\%)$

\begin{tabular}{lrrrrrr}
\hline MSCI world equity & 0.54 & 4.16 & -0.57 & 3.47 & 8.12 No & Yes \\
MSCI world sovereign bond & 0.52 & 1.91 & 0.37 & 3.49 & 4.15 Yes & Yes \\
Lehman Brothers cash composite & 0.34 & 0.15 & -0.69 & 2.06 & 14.73 No & No \\
CSFB Tremont Hedge fund & 0.89 & 2.40 & 0.10 & 4.77 & 16.76 No & No
\end{tabular}

composite

CSFB Tremont Hedge fund convertible

0.811 .37

$-1.47$

6.60

$113.52 \mathrm{No}$

No

arbitrage

CSFB Tremont Hedge fund dedicated

$-0.135 .10$

0.92

5.17

42.37 No

No

short bias

CSFB Tremont Hedge fund distressed

$1.07 \quad 1.97$

$-2.75$

19.13

$1525.22 \mathrm{No}$

No securities

CSFB Tremont Hedge fund event driven

$0.92 \quad 1.71$

$$
-3.46
$$

25.83

2988.13 No

No

0.831 .80

$-2.68$

19.83

1637.60 No

No

multi-strategy

CSFB Tremont Hedge fund emerging

$$
0.685 .03
$$

$-0.57$

6.71

$79.04 \mathrm{No}$

No

markets

CSFB Tremont Hedge fund fixed income

$0.56 \quad 1.1$

$-3.24$

19.35

1624.54 No

No

arbitrage

CSFB Tremont Hedge fund managed

$0.58 \quad 3.54$

0.04

3.41

0.94 Yes

Yes

futures

CSFB Tremont Hedge fund global macro

$1.17 \quad 3.4$

$$
-0.02
$$

5.07

$22.48 \mathrm{No}$

No

CSFB Tremont Hedge fund long/short

$0.98 \quad 3.11$

0.24

6.38

$61.10 \mathrm{No}$

No

equity

CSFB Tremont Hedge fund multi-strategy

CSFB Tremont Hedge fund equity

$\begin{array}{ll}0.73 & 1.27\end{array}$

$-1.27$

6.45

$0.25 \quad 3.21$

$96.04 \mathrm{No}$

No

0.830 .88

1.56 Yes

Yes market-neutral

CSFB Tremont Hedge fund risk arbitrage

0.671 .26

$-1.31$

9.19

236.98 No

No

The Jacque-Bera statistic is distributed as a $\chi^{2}$ distribution with two degrees of freedom. Its critical values at the 5 per cent and 1 per cent confidence levels are 5.991 and 9.210, respectively. Therefore, the null hypothesis of normality is rejected when the Jacque-Bera statistic has a higher value than the corresponding critical value at the respective confidence level. 
devoid of market risk, having roughly equal long and short positions in related securities. The most volatile strategy is Dedicated Short-Bias. It is notable and logical that the 'opportunistic' strategies are the most volatile: Dedicated ShortBias, Emerging Markets, MSCI World Equity, Managed Futures, Global Macro and Long/Short Equity are all directional strategies. This group is followed by mostly 'Event-Driven' strategies and is then followed by the 'relative value' strategies.

The descriptive statistics become more remarkable when looking at the third and fourth moments (ie skewness and kurtosis). Most of the hedge fund return series are negatively skewed and all strategies exhibit some level of excess kurtosis (ie greater than three). The most positively skewed strategy is that of Dedicated Short-Bias. This is most likely due to the funding mechanics of these portfolios. ${ }^{21}$

The most negatively skewed is that of the Event-Driven category. This has been noted in prior research by Agarwal and $\mathrm{Naik}^{2}$ who state: 'We find ... the Event Arbitrage index showing significant factor loading on risk factor corresponding to writing a OTM put option on SEP 500 index ... this result is intuitive as Event Arbitrage strategy involves the risk of deal failure. A larger fraction of deals fail when markets are down and the Event Arbitrage strategy incurs losses. In contrast, when markets are up a larger proportion of deals go through and the strategy makes profits. But the profits are unrelated to the extent by which the market goes up. Thus, the payoff to Event Arbitrage strategy resembles that obtained by writing a naked put option on the market'.

From a kurtosis point of view, the strategy with the highest kurtosis is that of Event-Driven, followed by its substrategy Event Driven MultiStrategy and then Fixed Income Arbitrage.

What is interesting to note about these two strategies (Event Driven and Fixed Income
Arbitrage) is that they are also marked by the most extreme cases of negative skewness and positive kurtosis. As observed by Davies et al.: ${ }^{17}$ 'Compounded by a high kurtosis (leptokurtosis), a negative skewed return distribution produces much higher possibilities for extreme events. ... that in most strategies, negative expected skewness goes with leptokurtosis on both individual fund and portfolio levels. Thus, it is preferable to analyse these two moments in tandem'. Another point of interest is that, under a mean-variance framework, volatility (variance or standard deviation) is used as a proxy for risk in circumstances where the return series can be characterised by a normal distribution. Where this is not the case, risk is better accounted for by the standard deviation in conjunction with the higher moments of the probability distribution. Where series have low standard deviations, they are often combined with low/negative skewness and high kurtosis.

Finally, all return series are subjected to the Jarque-Bera test statistic:

$$
\text { Jarque }- \text { Bera }=N\left(\frac{S^{2}}{6}+\frac{(K-3)^{2}}{24}\right)
$$

where $N$ is the number of observations, $S$ is the skewness and $K$ is the kurtosis of the series.

As evident in Table 1, most hedge fund index data are found to be not normally distributed, with the exception of Managed Futures and Equity Market Neutral, motivating the use of the higher moment optimisation technology described in the sixth section.

\section{METHODOLOGY}

Two portfolio construction approaches are applied in this paper. First, a conventional Markowitz mean-variance optimisation is employed, and secondly, a mean-variance-skewness-kurtosis 
(MVSK) optimisation. The second portfolio construction approach utilised in this study closely follows the PGP methodology of Davies et al. ${ }^{6}$ This facilitates the incorporation of both investor preferences beyond the mean-variance space (to higher moments) as well as a more complete representation of the probability distribution to effect efficient portfolio construction with hedge funds. This study is distinguished by using hedge fund index data as opposed to the single manager data used in Davies et al. ${ }^{6}$ In addition, this study augments this work by also addressing what proportion of a balanced portfolio (ie a portfolio consisting of equities, bonds and cash) should be invested in the hedge fund class.

PGP is useful in solving problems where multiple and competing objectives are present. As previously discussed, investors would like to maximise the first and third moments (mean and skewness) and minimise the second and fourth (variance and kurtosis). Davies et al. ${ }^{6}$ formulate the portfolio construction question as a multiple objective programming problem:

$$
\begin{aligned}
\text { Maximise } Z_{1}=X^{\mathrm{T}} \widetilde{R} & \\
\text { maximise } \quad Z_{3}= & \frac{T}{(T-1)(T-2)} \\
& \times \sum\left[\frac{\left(X^{\mathrm{T}}(\widetilde{R}-\widehat{R})\right.}{\sqrt{X^{\mathrm{T}} V X}}\right]^{3} \\
\text { minimise } \quad Z_{4}= & \left\{\frac{T(T+1)}{(T-1)(T-2)(T-3)}\right. \\
& \left.\times \sum\left[\frac{\left(X^{\mathrm{T}}(\widetilde{R}-\widehat{R})\right.}{\sqrt{X^{\mathrm{T}} V X}}\right]^{4}\right\} \\
& -\frac{3(T-1)^{2}}{(T-2)(T-3)}
\end{aligned}
$$

$$
\text { subject to } X^{\mathrm{T}} V X=A
$$

where, $X^{\mathrm{T}}=\left(x_{1}, x_{2}, \ldots, x_{n}\right)$ and $x_{i}$ is the capital weight percentage of the portfolio invested in the $i$ th asset. The asset can be a risky asset or risk-free. The $\mathrm{T}$ superscript denotes the transpose of the array in a matrix formula. $T$ is the number of observations in the time series (in this paper all series have 126 observations). $Z_{1}$ is the formula for portfolio mean return, $X^{\mathrm{T}} V X$ is portfolio variance, $Z_{3}$ is portfolio skewness and $Z_{4}$ is excess kurtosis. ${ }^{22} A$ denotes the level of variance pre-specified in the optimisation.

Combining the objectives in 6, 7, 8 and 9 into a single objective statement, a PGP can be expressed as:

$$
\begin{gathered}
\text { Minimise } Z=\left(1+d_{1}\right)^{\alpha}+\left(1+d_{3}\right)^{\beta} \\
+\left(1-d_{4}\right)^{\gamma} \\
\text { subject to } \quad X^{\mathrm{T}} \widetilde{R}+d_{1}=Z_{1}^{*} \\
\frac{T}{(T-1)(T-2)} \sum\left[\frac{\left(X^{\mathrm{T}}(\widetilde{R}-\widehat{R})\right.}{\sqrt{X^{\mathrm{T}} V X}}\right]^{3}+d_{3}=Z_{3}^{*} \\
\left\{\frac{T(T+1)}{(T-1)(T-2)(T-3)} \sum\left[\frac{\left(X^{\mathrm{T}}(\widetilde{R}-\widehat{R})\right.}{\sqrt{X^{\mathrm{T}} V X}}\right]^{4}\right\} \\
-\frac{3(T-1)^{2}}{(T-2)(T-3)}+d_{4}=Z_{4}^{*} \\
d_{1}, d_{3} \geq 0 \\
d_{4} \leq 0 \\
X^{\mathrm{T}} V X=A
\end{gathered}
$$

where $\alpha, \beta$ and $\gamma$ are the non-negative investor preferences for the mean, skewness and kurtosis of the portfolio return series. $Z_{1}^{*}$ is the mean return for the optimal mean-variance portfolio with a specified variance; $Z_{3}^{*}$ is the skewness value of the optimal skewness-variance portfolio with specified variance and $Z_{4}^{*}$ is the kurtosis value 
of the optimal kurtosis-variance portfolio with specified variance.

By construction, the mean return for an optimal MVSK portfolio will be lower than the mean return for an optimal mean-variance portfolio. Similarly, skewness for an optimal MVSK portfolio will be lower than that of an optimal skewness-variance portfolio. Therefore, $d_{1}$ and $d_{3}$ represent positive deviations from $Z_{1}^{*}$ and $Z_{3}^{*}$. Similarly for kurtosis, $d_{4}$ represents the negative deviation from $Z_{4}^{*}$.

Solving the PGP is a two-step process. First, the optimal values for $Z_{1}^{*}$ (expected return), $Z_{3}^{*}$ (skewness) and $Z_{4}^{*}$ (kurtosis), respectively are solved for a pre-specified level of variance. Secondly, these optimal values are substituted into restrictions 11,12 and 13 and a minimum value is found for the objective formula 10 . Davies et al. ${ }^{6}$ use their model to solve for optimal fund-of-hedge-fund portfolios under the further constraint of optimising for a variance of one. This study extends their work by comparing the outcome of the MVSK optimisation with the mean-variance methodology for varying levels of volatility.

\section{RESULTS}

The empirical results of this chapter are presented in two sections. The first section reports the fund-of-hedge-fund optimisation results. The second section presents the results with respect to an optimal asset allocation, including a traditional assets and a hedge fund portfolio. The sections are also divided into results obtained under a meanvariance framework and those obtained under the PGP MVSK methodology. The section concludes with a comparative performance evaluation.

\section{Fund-of-hedge-funds optimisation}

This section presents results using data from the CSFB Tremont hedge fund indices. All CSFB Tremont indices are included in this analysis except the Composite index, as the objective of this section is to derive an optimal composite.

\section{Mean-variance optimisation}

As stated in the previous section, a variance minimisation technique was used in this procedure. Minimum variance portfolios are found for 21 reference points of return in this hedge fund set. The points are derived by creating 20 equidistant points between the minimum average monthly return ${ }^{23}$ and the maximum average monthly return ${ }^{24}$ of all the indices in the set. The results are presented in Table 2.

Table 2 splits the output into two panels: Panel A shows descriptive statistics of the output while Panel B presents the allocation in portfolios 1 through 21. From Table 2 and Figure 1 it can be seen that only portfolios 12 through 21 are part of the efficient frontier. For portfolios 1 through 11 there exists a portfolio on the minimum-variance frontier for which there is a point of higher return for the same quantum of volatility (standard deviation). This means that portfolios 1-11 are not an element of the efficient frontier set.

In the inefficient portfolios 1 through 5 , the mean-variance optimisation initially allocates capital to Dedicated Short-Bias and Emerging Markets. The mean-variance model uses Dedicated Short-Bias as a means of initially reducing portfolio return. These two strategies have a correlation coefficient value of -0.63 and thus the Emerging Markets exposure reduces portfolio volatility. From portfolios 6 to 11, these 
Table 2: Optimal fund of hedge fund portfolios under a mean-variance framework

Panel A: Portfolio expected return and risk statistics

\begin{tabular}{|c|c|c|c|c|c|}
\hline Portfolio & Expected return (\%) & Variance (\%) & Standard Deviation (\%) & Skewness & Kurtosis \\
\hline 1 & -0.13 & 0.26 & 5.08 & 0.93 & 2.30 \\
\hline 2 & -0.07 & 0.20 & 4.46 & 0.83 & 1.80 \\
\hline 3 & 0.00 & 0.15 & 3.87 & 0.67 & 1.18 \\
\hline 4 & 0.06 & 0.11 & 3.33 & 0.46 & 0.48 \\
\hline 5 & 0.13 & 0.08 & 2.86 & 0.18 & -0.14 \\
\hline 6 & 0.19 & 0.06 & 2.45 & 0.10 & -0.10 \\
\hline 7 & 0.26 & 0.04 & 2.06 & -0.02 & 0.10 \\
\hline 8 & 0.32 & 0.03 & 1.68 & -0.15 & 0.38 \\
\hline 9 & 0.39 & 0.02 & 1.32 & -0.36 & 1.07 \\
\hline 10 & 0.45 & 0.01 & 1.01 & -0.67 & 2.24 \\
\hline 11 & 0.52 & 0.01 & 0.78 & -0.97 & 2.86 \\
\hline 12 & 0.58 & 0.00 & 0.64 & -0.77 & 1.58 \\
\hline 13 & 0.65 & 0.00 & 0.57 & -0.39 & -0.27 \\
\hline 14 & 0.71 & 0.00 & 0.59 & -0.16 & -0.28 \\
\hline 15 & 0.78 & 0.00 & 0.66 & -0.09 & 0.53 \\
\hline 16 & 0.85 & 0.01 & 0.78 & -0.18 & 2.10 \\
\hline 17 & 0.91 & 0.01 & 0.98 & -0.57 & 4.45 \\
\hline 18 & 0.98 & 0.02 & 1.26 & -1.18 & 7.59 \\
\hline 19 & 1.04 & 0.03 & 1.60 & -1.57 & 9.04 \\
\hline 20 & 1.11 & 0.04 & 2.01 & -1.18 & 6.15 \\
\hline 21 & 1.17 & 0.12 & 3.40 & -0.02 & 2.20 \\
\hline
\end{tabular}

Panel B: Percentage allocation to hedge fund strategy in fund-of-hedge-fund portfolio

\begin{tabular}{|c|c|c|c|c|c|c|c|c|c|c|c|c|}
\hline $\begin{array}{l}\text { Convertible } \\
\text { arbitrage } \\
(\%)\end{array}$ & $\begin{array}{l}\text { Dedicated } \\
\text { short-bias } \\
(\%)\end{array}$ & $\begin{array}{l}\text { Distressed } \\
\text { securities } \\
(\%)\end{array}$ & $\begin{array}{l}\text { Emerging } \\
\text { markets } \\
(\%)\end{array}$ & $\begin{array}{l}\text { Equity } \\
\text { market- } \\
\text { neutral } \\
(\%)\end{array}$ & $\begin{array}{l}\text { Event } \\
\text { driven } \\
(\%)\end{array}$ & $\begin{array}{l}\text { Event } \\
\text { driven } \\
\text { multi- } \\
\text { strategy } \\
(\%)\end{array}$ & $\begin{array}{l}\text { Fixed } \\
\text { income } \\
\text { arbitrage } \\
(\%)\end{array}$ & $\begin{array}{l}\text { Global } \\
\text { macro } \\
(\%)\end{array}$ & $\begin{array}{l}\text { Multi- } \\
\text { strategy } \\
(\%)\end{array}$ & $\begin{array}{l}\text { Risk } \\
\text { arbitrage } \\
(\%)\end{array}$ & $\begin{array}{l}\text { Long/ } \\
\text { short } \\
\text { equity } \\
(\%)\end{array}$ & $\begin{array}{l}\text { Managed } \\
\text { futures } \\
(\%)\end{array}$ \\
\hline 0 & 100 & 0 & 0 & 0 & 0 & 0 & 0 & 0 & 0 & 0 & 0 & 0 \\
\hline 0 & 92 & 0 & 8 & 0 & 0 & 0 & 0 & 0 & 0 & 0 & 0 & 0 \\
\hline 0 & 84 & 0 & 16 & 0 & 0 & 0 & 0 & 0 & 0 & 0 & 0 & 0 \\
\hline 0 & 76 & 0 & 24 & 0 & 0 & 0 & 0 & 0 & 0 & 0 & 0 & 0 \\
\hline 0 & 68 & 0 & 32 & 0 & 0 & 0 & 0 & 0 & 0 & 0 & 0 & 0 \\
\hline 0 & 58 & 0 & 27 & 0 & 0 & 0 & 15 & 0 & 0 & 0 & 0 & 0 \\
\hline
\end{tabular}


Table 2: $\quad$ Continued

Panel B: Percentage allocation to hedge fund strategy in fund-of-hedge-fund portfolio

\begin{tabular}{|c|c|c|c|c|c|c|c|c|c|c|c|c|}
\hline $\begin{array}{l}\text { Convertible } \\
\text { arbitrage } \\
(\%)\end{array}$ & $\begin{array}{l}\text { Dedicated } \\
\text { short-bias } \\
(\%)\end{array}$ & $\begin{array}{l}\text { Distressed } \\
\text { securities } \\
(\%)\end{array}$ & $\begin{array}{l}\text { Emerging } \\
\text { markets } \\
(\%)\end{array}$ & $\begin{array}{l}\text { Equity } \\
\text { market- } \\
\text { neutral } \\
(\%)\end{array}$ & $\begin{array}{l}\text { Event } \\
\text { driven } \\
(\%)\end{array}$ & $\begin{array}{l}\text { Event } \\
\text { driven } \\
\text { multi- } \\
\text { strategy } \\
(\%)\end{array}$ & $\begin{array}{l}\text { Fixed } \\
\text { income } \\
\text { arbitrage } \\
(\%)\end{array}$ & $\begin{array}{l}\text { Global } \\
\text { macro } \\
(\%)\end{array}$ & $\begin{array}{l}\text { Multi- } \\
\text { strategy } \\
(\%)\end{array}$ & $\begin{array}{l}\text { Risk } \\
\text { arbitrage } \\
(\%)\end{array}$ & $\begin{array}{l}\text { Long/ } \\
\text { short } \\
\text { equity } \\
(\%)\end{array}$ & $\begin{array}{l}\text { Managed } \\
\text { futures } \\
(\%)\end{array}$ \\
\hline 0 & 48 & 0 & 22 & 0 & 0 & 0 & 27 & 0 & 0 & 3 & 0 & 0 \\
\hline 0 & 39 & 0 & 17 & 0 & 0 & 0 & 31 & 0 & 0 & 13 & 0 & 0 \\
\hline 0 & 31 & 0 & 12 & 0 & 0 & 0 & 34 & 0 & 0 & 23 & 0 & 0 \\
\hline 0 & 22 & 0 & 7 & 0 & 0 & 0 & 37 & 0 & 0 & 33 & 0 & 1 \\
\hline 0 & 14 & 0 & 3 & 0 & 0 & 0 & 37 & 0 & 3 & 39 & 0 & 4 \\
\hline 0 & 10 & 0 & 1 & 17 & 0 & 0 & 29 & 0 & 6 & 32 & 0 & 3 \\
\hline 0 & 8 & 0 & 0 & 36 & 0 & 0 & 21 & 0 & 8 & 24 & 1 & 1 \\
\hline 0 & 7 & 8 & 0 & 46 & 0 & 0 & 11 & 0 & 10 & 14 & 1 & 0 \\
\hline 0 & 7 & 17 & 0 & 55 & 0 & 0 & 1 & 1 & 12 & 5 & 1 & 0 \\
\hline 0 & 4 & 22 & 0 & 60 & 0 & 0 & 0 & 4 & 9 & 0 & 0 & 0 \\
\hline 0 & 0 & 26 & 0 & 62 & 0 & 0 & 0 & 8 & 4 & 0 & 0 & 0 \\
\hline 0 & 0 & 41 & 0 & 45 & 0 & 0 & 0 & 14 & 0 & 0 & 0 & 0 \\
\hline 0 & 0 & 59 & 0 & 21 & 0 & 0 & 0 & 21 & 0 & 0 & 0 & 0 \\
\hline 0 & 0 & 64 & 0 & 0 & 0 & 0 & 0 & 36 & 0 & 0 & 0 & 0 \\
\hline 0 & 0 & 0 & 0 & 0 & 0 & 0 & 0 & 100 & 0 & 0 & 0 & 0 \\
\hline
\end{tabular}

Panel A presents the portfolio mean return, standard deviation and the higher moments while Panel B shows the allocation to the individual hedge fund strategies.

two allocations are reduced in favour of Fixed Income Arbitrage and Risk Arbitrage (with small allocations to Multi-Strategy and Managed Futures).

An examination of the efficient portfolios 12-21 shows that almost all these portfolios contain Equity Market-Neutral allocations as well as Distressed Securities. Only at the extreme levels of expected return do Global Macro funds play a role. By construction, the efficient frontier is increasing in volatility from the minimum variance point to the point of maximum return.
The mean-variance model, however, does not evaluate the impact of higher moments on portfolio design. It must be noted from Table 2 that from the minimum-variance point skewness initially increases (from portfolio 13 to 16$)$ and then decreases. Portfolio kurtosis initially falls from the minimum-variance point (portfolio 13) and then increases (portfolio 15). Under a mean-variance regime, portfolio 13 is the minimum-variance portfolio. This can also be expressed as the lowest risk portfolio under this framework. Taking higher 


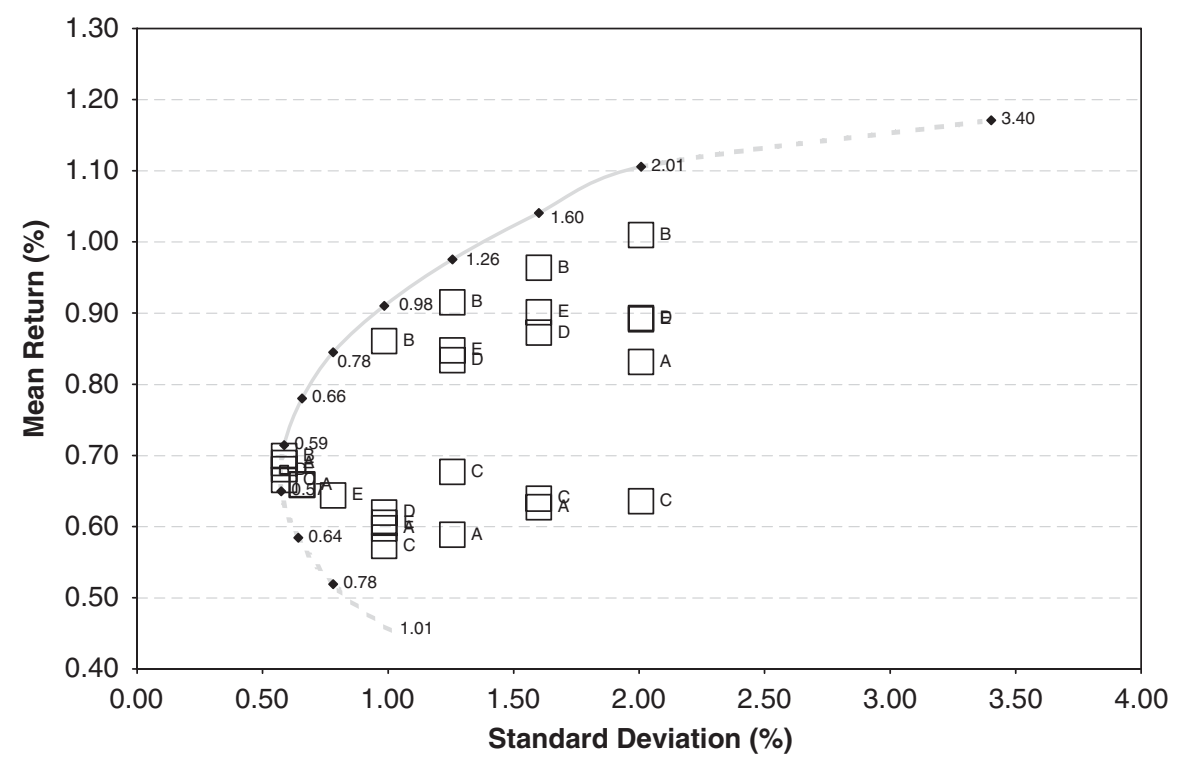

Figure 1: Optimal fund-of-hedge-fund portfolios minimum-variance frontier with comparative MVSK portfolios.

The solid line indicates the segment of the frontier for which MVSK portfolios are modelled, while the broken line denotes the remainder of the minimum-variance frontier. The squares plot the expected mean return and standard deviation for the MVSK portfolios. It is clear that optimising for higher moments while holding variance (or standard deviation) constant results in a deterioration of mean return. Investor profiles A-E are presented in Table 3.

moments into account may yield a slightly different result, as portfolios 13 and 14 have more favourable third and fourth moments (higher skewness and still low kurtosis). Thus it can be argued that depending on particular investor preferences, either portfolio 13 or 14 could, in fact, be the minimum risk portfolio.

Examining the more volatile portfolios (16-19), it can also be argued that the meanvariance framework does not provide the full risk picture. In these portfolios, it can be seen that skewness decreases and kurtosis increases. As noted in the fifth section, this is an unfavourable combination as this increases the likelihood of more severe negative returns.

\section{PGP optimisation for MVSK}

Upon calculating the mean-variance efficient frontier, 20 equidistant standard deviation points along the frontier are used as 'anchors' to enable comparison with the PGP regime. Furthermore, these particular anchor points are along the section of the efficient frontier beyond the minimum variance portfolio and before the maximum expected return portfolio. The standard deviation anchors are 0.59 per cent, 0.66 per cent, 0.78 per cent, 0.98 per cent, 1.26 per cent, 1.60 per cent and 2.01 per cent.

Utilising these anchor points, PGP-optimised MVSK portfolios are modelled for five different profiles of investor preferences with respect to expected return, skewness and kurtosis. 
Table 3: Preference scenarios in PGP MVSK optimisation

\begin{tabular}{llllll}
\hline & $A$ & $B$ & $C$ & $D$ & $E$ \\
\hline$\alpha$ & 1 & 3 & 1 & 3 & 2 \\
$\beta$ & 3 & 1 & 0 & 2 & 3 \\
$\gamma$ & 0 & 0 & 3 & 1 & 1 \\
\hline
\end{tabular}

Under this methodology, $\alpha, \beta$ and $\gamma$ denote investor preferences for mean return, skewness and kurtosis, respectively. These preferences form part of the objective function $Z$. Three denotes that a relatively high level of investor utility is derived from this moment, 2 a medium level and 1 a low level. Zero indicates no preference.

$\alpha$ denotes investor preference over expected return, while $\beta$ and $\gamma$ denote preference for skewness and kurtosis, respectively. The five modelled profiles (labelled A-E) for each anchor point are displayed in Table 3.

Figure 1 presents a section of the original mean-variance frontier calculated in Meanvariation optimisation section. The frontier is augmented by the addition of the square indicators, which show the expected return/ standard deviation point for an MVSKoptimised portfolio. The square indicators are marked by their labels (A-E), which denote the respective profiles to which they refer. It can be noted from Figure 1 that the MVSK-optimised portfolios differ substantially in return from the mean-variance efficient frontier portfolios. It is also clear that scenarios B and E generally map closer to the efficient frontier, while those of $\mathrm{A}$ and $\mathrm{C}$ map further away. These results are intrinsic to the MVSK model, for under scenarios B and $\mathrm{E}$ greater preference is placed on portfolio return ( $\alpha$ (mean or expected return preference) values of 3 and 2 respectively). On the other hand, scenarios $\mathrm{A}$ and $\mathrm{C}$ have maximum preference for one of the higher moments ( $\beta$ (skewness preference) value of 3 and $\gamma$ (kurtosis preference) value of 3 , respectively).
A number of notable observations can be made from Figure 1. First, all MVSK portfolios appear below the mean-variance efficient frontier. This shows that the optimisation of a fund-of-hedge-fund portfolio in the MVSK space is one of the competing objectives. Therefore, there is a consistent trade-off between the four moments. This finding is the same as that of Davies et al. ${ }^{6}$ In other words, holding variance constant at a pre-specified level and optimising for the other three moments must lead to deterioration in the expected portfolio return. If this were not the case, optimising for skewness and kurtosis would be at no cost to the investor and would effectively constitute a 'free lunch'.

Secondly, as the standard deviation increases along the efficient frontier, the divergence between the mean-variance-optimised portfolio and the MVSK-optimised portfolios increases. The reason for this is two-fold. As the volatility of the portfolio increases, an offsetting large reduction in expected return must be sacrificed in order to improve the skewness and kurtosis of the portfolio. Furthermore, under the mean-variance regime, the portfolios optimised beyond the minimum-variance portfolio initially have improving higher moment risk 
statistics. From portfolio 15 onwards, the optimal mean-variance portfolios have deteriorating skewness and kurtosis values. Thus, in order to improve these attributes, an ever larger return forfeit is required.

The portfolios also differ substantially in composition. Using the standard deviation anchor point of 1.26 per cent as an example, the output from the model is displayed in Table 4.

First, it must be noted that the MVSK portfolios A-E all have higher levels of skewness and lower levels of kurtosis than the meanvariance portfolio. Secondly, the MVSK are substantially different in their composition.

Table 4: Comparison of optimal fund-of-hedge-fund portfolios under a mean-variance regime and those under an MVSK framework

\begin{tabular}{|c|c|c|c|c|c|c|}
\hline Scenario & $A$ & $B$ & $C$ & $D$ & E & Mean-variance \\
\hline$\alpha$ & 1 & 3 & 1 & 3 & 2 & 3 \\
\hline$\beta$ & 3 & 1 & 0 & 2 & 3 & 0 \\
\hline$\gamma$ & 0 & 0 & 3 & 1 & 1 & 0 \\
\hline Mean & 0.59 & 0.91 & 0.68 & 0.83 & 0.85 & 0.98 \\
\hline Variance & 1.58 & 1.58 & 1.58 & 1.58 & 1.58 & 1.58 \\
\hline Skewness & 0.75 & 0.72 & -0.01 & 0.53 & 0.61 & -1.18 \\
\hline Kurtosis & 1.88 & 1.47 & -0.65 & 0.21 & 0.49 & 7.59 \\
\hline Standard deviation & 1.26 & 1.26 & 1.26 & 1.26 & 1.26 & 1.26 \\
\hline Convertible arbitrage (\%) & 0 & 0 & 10 & 10 & 2 & 0 \\
\hline Dedicated short-bias (\%) & 21 & 0 & 2 & 0 & 0 & 0 \\
\hline Distressed securities (\%) & 0 & 0 & 1 & 0 & 0 & 41 \\
\hline Emerging markets (\%) & 0 & 0 & 12 & 0 & 0 & 0 \\
\hline Equity market-neutral (\%) & 49 & 69 & 7 & 28 & 36 & 45 \\
\hline Event driven (\%) & 0 & 0 & 3 & 0 & 0 & 0 \\
\hline Event driven multi-strategy (\%) & 0 & 0 & 7 & 0 & 0 & 0 \\
\hline Fixed income arbitrage & 0 & 0 & 17 & 0 & 0 & 0 \\
\hline Global macro & 1 & 27 & 0 & 9 & 12 & 14 \\
\hline Multi-strategy (\%) & 16 & 0 & 7 & 14 & 15 & 0 \\
\hline Risk arbitrage (\%) & 0 & 0 & 3 & 0 & 0 & 0 \\
\hline Long/short equity (\%) & 0 & 0 & 0 & 20 & 19 & 0 \\
\hline Managed futures (\%) & 14 & 4 & 28 & 19 & 16 & 0 \\
\hline
\end{tabular}

The portfolios are constructed under the MVSK PGP model depending on the investor preferences specified. A simple mean-variance portfolio can be run as a special case with the preferences of maximising return with no preference for either skewness or kurtosis. For the purpose of this comparison, a fixed portfolio standard deviation of 1.26 per cent per month is used. 
With the exception of the 1 per cent allocation in portfolio $\mathrm{C}$, all the MVSK award no weighting to the Distressed Securities category. This is in stark contrast with the mean-variance portfolio, which has a 41 per cent holding. Furthermore, with the exception of some inconsequential allocations, almost none of the optimal portfolios include strategies that exhibit the hazardous combination of negative skewness and high kurtosis, that is, Distressed Securities, Event Driven, Event Driven Multi-Strategy, Fixed Income Arbitrage and Risk Arbitrage. For example, Distressed Securities by their very nature imbue a high probability of bankruptcy, while Fixed Income Arbitrage bears credit risk - so well borne out by the LTCM $^{25}$ and more recent sub-prime disasters.

All portfolios include an allocation to the Equity Market Neutral category. As shown in the fifth section, the Equity Market Neutral index exhibits relatively low levels of volatility and kurtosis, as well as close to zero skewness. By pairing off similar long and short positions, systematic risks are reduced, yielding a truly low-risk strategy.

\section{Performance evaluation}

If MVSK portfolios are in fact more efficient than mean-variance portfolios, then performance appraisal measures should reflect this. For the optimised portfolios under the anchor point 1.26 per cent, three performance functions (Sharpe and Sortino ratio as well as the Omega function) are calculated and presented in Table 5.

By construction, the mean-varianceoptimised portfolio has a superior Sharpe ratio to the MVSK portfolios. Examining the performance under the Sortino ratio, all MVSK portfolios are superior, with the exception of portfolio A. Given that the 'risk denominator' in the Sortino ratio is downside deviation, additionally optimising for the higher moments of skewness and kurtosis should provide some benefit. Portfolio A optimises heavily on the skewness preference and this appears to have lowered the overall return substantially below that of the other portfolios, resulting in a lower Sortino score. As mentioned, the Omega function observes the mass of a probability density function above a pre-determined

Table 5: Performance measures for optimal fund-of-hedge-fund portfolios

\begin{tabular}{lllllll}
\hline Investor profile & $A$ & $B$ & $C$ & $D$ & $E$ & Mean-variance \\
\hline Sharpe ratio & 0.20 & 0.45 & 0.27 & 0.39 & 0.40 & 0.50 \\
Sortino ratio & 0.41 & 1.15 & 0.59 & 1.10 & 1.11 & 0.50 \\
Omega & 1.010996695 & 1.010996695 & 1.010996694 & 1.010996695 & 1.010996689 & 1.010909474 \\
Omega rank & 1 & 3 & 4 & 2 & 5 & 6 \\
\hline
\end{tabular}

The performance measures are presented below for different investor preference scenarios for the anchor point of 1.26 per cent standard deviation. The Sharpe Ratio shows excess return (above the risk-free rate) per unit of volatility. The Sortino Ratio shows excess return (above the risk-free rate) per unit of downside volatility. The Omega function is a ratio of the area above to the area below a threshold level, of a probability distribution. The threshold level used is that of the risk-free rate to ensure comparability with the other ratios. The Omega rank refers to the ranking of the Omega function in descending order with 1 indicating the most preferred portfolio. 
threshold level - in this case, the risk-free rate for which the Lehman Brothers US Cash Composite is a proxy. According to this measure, the MVSK portfolios all outperform the mean-variance portfolio.

\section{Asset allocation with hedge funds optimisation}

This section attempts to determine what proportion of their assets investors should allocate in a traditional portfolio that includes an allocation to hedge funds. The model utilises the MSCI World Equity and World Sovereign Bond indices to proxy for diversified global equity and bond portfolios. Furthermore, the data series from the CSFB Tremont Composite Hedge
Fund Index is employed as a proxy for a welldiversified fund of hedge funds.

\section{Mean-variance optimisation}

The same technique as applied in the previous section is utilised with the above data set. Once more, minimum-variance portfolios are found for 20 equidistant points of return among the four assets. ${ }^{26}$ The results of this mean-variance model are presented in Table 6 and graphically in Figure 2. Examining these portfolios shows that unlike the previous minimum-variance frontier, this frontier has no inefficient segment.

The optimal mean-variance portfolios make no allocation to the World Equity index at all. This may be due to the World Equity and World

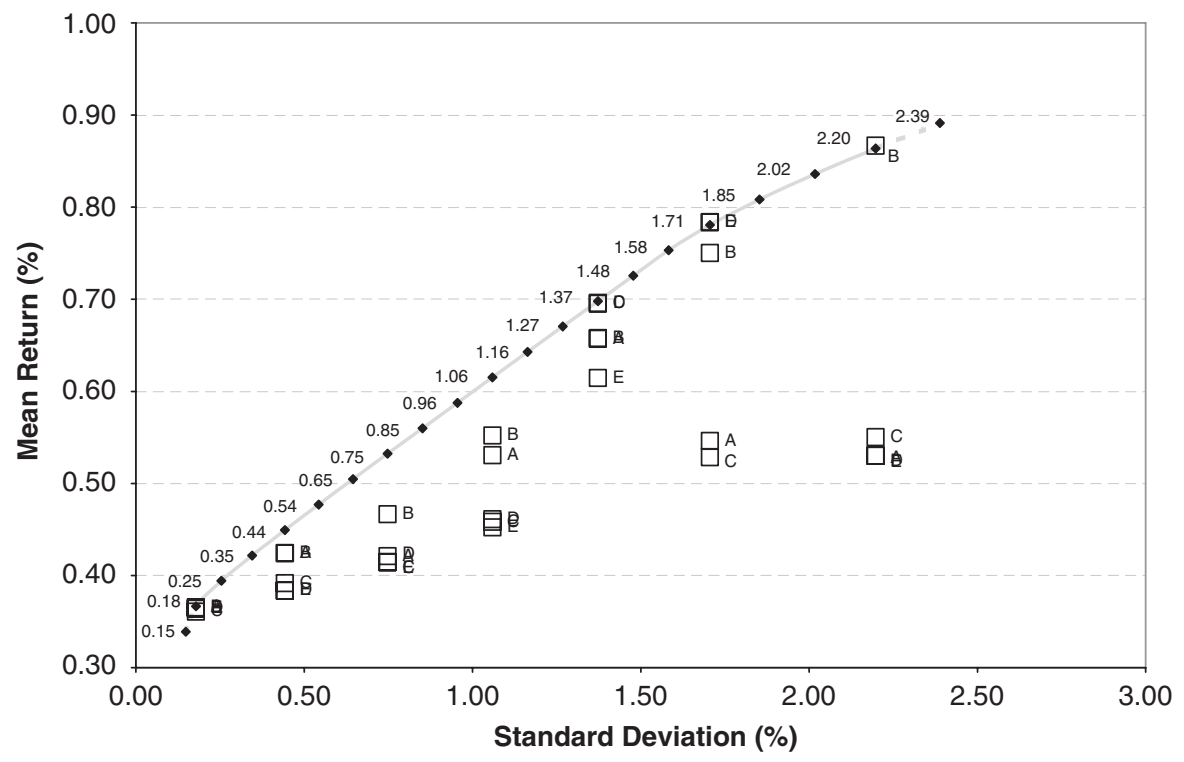

Figure 2: Optimal balanced portfolios under a mean-variance framework with comparative MVSK portfolios.

The solid line indicates the segment of the frontier for which MVSK portfolios are modelled, while the broken line denotes the remainder of the minimum-variance frontier. The squares plot the expected mean return and standard deviation for the MVSK portfolios. It is clear that optimising for higher moments while holding variance (or standard deviation) constant results in a deterioration of mean return. Investor profiles $A-E$ are presented in Table 3. 
Sovereign Bond indices having very similar average monthly returns over the sample period but World Sovereign Bond having a much lower level of volatility than World Equities. ${ }^{27}$ Under a framework that rewards expected returns per unit of volatility, this is an intuitive explanation.

The optimal portfolios initially allocate capital to cash and gradually increase exposure to the World Sovereign Bond index and the Hedge Fund Composite as volatility increases. The Sovereign Bond allocation increases in proportion until portfolio 16 and then declines to zero. This indicates that beyond portfolio 16 , the correlation or covariance benefit from a volatility reduction perspective is surpassed by the return offered by the hedge fund composite. The US Cash Composite allocation decreases consistently until portfolio 16 where it reaches zero.

Examining the risk moments of variance, skewness and kurtosis, it can be seen that volatility rises across the frontier while the skewness and kurtosis values are more dynamic. Skewness initially increases across portfolios 1-4, then declines until portfolio 16 and then increases to the maximum return portfolio. Kurtosis generally increases with variance across this optimisation but increases more rapidly from portfolio 16 onwards.

In terms of portfolio composition, the MVSK and mean-variance portfolios are substantially different. Using the standard deviation anchor point of 1.06 per cent as an example, the output is presented in Table 7 .

Again, all the MVSK portfolios have a lower level of return at each volatility level than the mean-variance portfolio. For the MVSK portfolios that have no preference for either higher moment (viz. scenarios A, B and C), that particular moment is worse than the mean-variance portfolio. It is interesting to note that some of the MVSK portfolios do allocate to the World Equity asset, unlike the mean-variance portfolio, which holds no World Equity. This shows that its inclusion in a diversified portfolio has a benefit of either improving skewness or reducing kurtosis when blended with these other investments.

A key observation is the fact that the MVSK portfolios all allocate substantially lower weightings to hedge funds than the meanvariance portfolio. In fact, scenario $\mathrm{E}$ makes no allocation to the Hedge Fund Composite at all. This is in stark contrast to the findings above as well as to those by prior research covered in the third section, where mean-variance portfolios allocate large amounts of capital to hedge funds in balanced diversified portfolios. Furthermore, comparing the mean-variance allocation in Table 7 to profile B (where merely a unit of preference for positive skewness is added) reveals that the hedge fund allocation almost halves from 41 per cent to 21 per cent as a result of a relatively minor change in utility function! It is clear that considering higher moments leads to a more tempered allocation to hedge funds.

\section{Performance evaluation}

Using the same format as before, Table 8 presents the three performance criteria for the anchor point 1.06 per cent.

The performance criteria are not as clear in expressing support for the MVSK portfolios. As in the previous section, the mean-variance portfolio should always have the best Sharpe ratio by construction.

The Omega function was again calculated using the risk-free cash return as a threshold level in order to make it comparable with the Sharpe 
Table 6: Optimal balanced portfolios under a mean-variance framework

Panel A: Portfolio expected return and risk statistics

\begin{tabular}{|c|c|c|c|c|c|}
\hline Portfolio number & Expected return (\%) & Variance (\%) & Standard deviation (\%) & Skewness & Kurtosis \\
\hline 1 & 0.34 & 0.00 & 0.15 & -0.70 & -0.93 \\
\hline 2 & 0.37 & 0.00 & 0.18 & -0.15 & -0.51 \\
\hline 3 & 0.39 & 0.00 & 0.25 & 0.11 & -0.05 \\
\hline 4 & 0.42 & 0.00 & 0.35 & 0.12 & 0.25 \\
\hline 5 & 0.45 & 0.00 & 0.44 & 0.09 & 0.41 \\
\hline 6 & 0.48 & 0.00 & 0.54 & 0.05 & 0.51 \\
\hline 7 & 0.50 & 0.00 & 0.65 & 0.02 & 0.57 \\
\hline 8 & 0.53 & 0.01 & 0.75 & 0.00 & 0.61 \\
\hline 9 & 0.56 & 0.01 & 0.85 & -0.02 & 0.64 \\
\hline 10 & 0.59 & 0.01 & 0.96 & -0.03 & 0.66 \\
\hline 11 & 0.62 & 0.01 & 1.06 & -0.04 & 0.68 \\
\hline 12 & 0.64 & 0.01 & 1.16 & -0.05 & 0.69 \\
\hline 13 & 0.67 & 0.02 & 1.27 & -0.06 & 0.70 \\
\hline 14 & 0.70 & 0.02 & 1.37 & -0.07 & 0.71 \\
\hline 15 & 0.73 & 0.02 & 1.48 & -0.08 & 0.72 \\
\hline 16 & 0.75 & 0.03 & 1.58 & -0.08 & 0.76 \\
\hline 17 & 0.78 & 0.03 & 1.71 & -0.04 & 1.01 \\
\hline 18 & 0.81 & 0.03 & 1.85 & 0.00 & 1.29 \\
\hline 19 & 0.84 & 0.04 & 2.02 & 0.04 & 1.54 \\
\hline 20 & 0.86 & 0.05 & 2.20 & 0.08 & 1.74 \\
\hline 21 & 0.89 & 0.06 & 2.39 & 0.10 & 1.90 \\
\hline
\end{tabular}

Panel B: Percentage allocation to investment in diversified portfolio

\begin{tabular}{lllc}
\hline Hedge fund composite (\%) & World equity (\%) & World sovereign bond (\%) & US cash composite (\%) \\
\hline 0 & 0 & 0 & 90 \\
4 & 0 & 3 & 86 \\
8 & 0 & 6 & 79 \\
12 & 0 & 9 & 73 \\
16 & 0 & 11 & 66 \\
20 & 0 & 14 & 59 \\
25 & 0 & 16 & 52 \\
29 & 0 & 19 & 46 \\
33 & 0 & 21 & 39 \\
\hline
\end{tabular}


Table 6: $\quad$ Continued

Panel B: Percentage allocation to investment in diversified portfolio

\begin{tabular}{llll}
\hline Hedge fund composite (\%) & World equity (\%) & World sovereign bond (\%) & US cash composite (\%) \\
\hline 41 & 0 & 27 & 32 \\
45 & 0 & 29 & 26 \\
49 & 0 & 32 & 19 \\
54 & 0 & 34 & 6 \\
58 & 0 & 37 & 0 \\
62 & 0 & 38 & 0 \\
70 & 0 & 30 & 0 \\
77 & 0 & 23 & 0 \\
85 & 0 & 15 & 0 \\
92 & 0 & 8 & 0 \\
\hline
\end{tabular}

Panel A reflects portfolio expected return and the higher moment risk statistics while Panel B shows the detailed allocation to individual assets.

Table 7: Comparison of optimal balanced portfolios under a mean-variance regime and under an MVSK framework

\begin{tabular}{lcccccc}
\hline Scenario & $A$ & $B$ & $C$ & $D$ & $E$ & Mean-variance \\
\hline$\alpha$ & 1 & 3 & 1 & 3 & 2 & 3 \\
$\beta$ & 3 & 1 & 0 & 2 & 3 & 0 \\
$\gamma$ & 0 & 0 & 3 & 1 & 1 & 0 \\
Mean & & & & & & \\
Variance & 0.53 & 0.55 & 0.46 & 0.46 & 0.45 & 0.62 \\
Skewness & 1.12 & 1.12 & 1.12 & 1.12 & 1.12 & 1.12 \\
Kurtosis & 0.21 & 0.15 & -0.27 & -0.01 & 0.21 & -0.06 \\
Standard deviation & 1.08 & 1.08 & -0.08 & 0.27 & 0.68 & 0.72 \\
Hedge fund composite (\%) & 1.06 & 1.06 & 1.06 & 1.06 & 1.06 & 1.06 \\
World equity (\%) & 16 & 21 & 5 & 2 & 0 & 41 \\
World sovereign bond (\%) & 0 & 0 & 20 & 15 & 6 & 0 \\
US cash composite (\%) & 54 & 52 & 26 & 41 & 53 & 27 \\
\hline
\end{tabular}

The portfolios are constructed under the MVSK PGP model depending on the investor preferences specified. A simple mean-variance portfolio can be run as a special case with the preferences of maximising return with no preference for either skewness or kurtosis. For the purpose of this comparison, a fixed portfolio standard deviation of 1.06 per cent per month is used. 
Table 8: Performance measures for optimal balanced portfolios

\begin{tabular}{lllllll}
\hline Investor profile & $A$ & $B$ & $C$ & $D$ & $E$ & Mean-variance \\
\hline Sharpe ratio & 0.18 & 0.20 & 0.11 & 0.11 & 0.10 & 0.26 \\
Sortino ratio & 0.31 & 0.33 & 0.18 & 0.22 & 0.18 & 0.41 \\
Omega & 1.015485507 & 1.015485497 & 1.015485535 & 1.015485499 & 1.015485526 & 1.015383107 \\
Omega rank & 3 & 5 & 1 & 4 & 2 & 6 \\
\hline
\end{tabular}

The performance measures are presented below for different investor preference scenarios for the anchor point of 1.06 per cent standard deviation. The Sharpe Ratio shows excess return (above the risk-free rate) per unit of volatility. The Sortino Ratio shows excess return (above the risk-free rate) per unit of downside volatility. The Omega function is a ratio of the area above to the area below a threshold level, of a probability distribution. The threshold level used is that of the risk-free rate to ensure comparability with the other ratios. The Omega rank refers to the ranking of the Omega function in descending order with 1 indicating the most preferred portfolio.

and Sortino ratios. The Omega function ranks all the MVSK portfolios above that of the meanvariance portfolio. This is the case for all anchor points across the mean-variance frontier. The mean-variance portfolio, however, also shows a superior Sortino ratio when compared with the MVSK portfolios. It is remarkable that scenario B displays the most attractive Sharpe and Sortino ratios within the MVSK portfolios but also ranks lowest when evaluated on the Omega function criterion. Scenario C, which has the highest Omega score, in fact has the most negative skewness, but compensates by also having the lowest kurtosis.

\section{CONCLUSION}

This paper finds that almost all hedge fund strategies have non-normal distributions. In contrast, the Jarque-Bera test for the normality of the equity and bond indices was unable to reject the null hypothesis of normality at the 5 per cent level. Many hedge fund strategies (especially the Event-Driven category and Fixed Income Arbitrage) have negatively skewed returns as well as leptokurtosis ('fat-tails'). Through analysis of these two higher moments together, it can be concluded that these strategies have a substantially higher probability of extreme losses than suggested by a normal distribution. As an example, research by Agarwal and Naik ${ }^{2}$ has shown that the payoff to the broad category of Event-Driven hedge fund strategies is akin to short put option positions on the market. This means that this strategy will yield low volatility consistent returns until the occurrence of an extreme adverse event, whereupon the strategy will make substantial losses. Based on the features of the probability distribution of this strategy, more specifically significant negative skewness and a high level of kurtosis, these extreme adverse events occur more often than suggested by a normal distribution. A similar rationale can be made for other hedge fund strategies, and Fixed Income Arbitrage in particular.

It is found that the results of an optimisation under a conventional mean-variance regime and those of the MVSK framework are substantially different. Comparing portfolios with the same level of volatility shows that the MVSK 
portfolios deliver lower returns than meanvariance optimised portfolios on a meanvariance plane. This illustrates that further optimising for higher moments has an (ex post) cost and that measuring the returns of portfolios that include hedge funds on a purely meanvariance level is deceptive. Similarly, it has been shown that optimising on a naive mean-variance basis can introduce the hazard of reducing skewness and increasing kurtosis in a portfolio further raising the probability of extreme adverse events. The compositions of the mean-variance portfolios and MVSK portfolios are also substantially different. The MVSK portfolios tend to be more diversified than the meanvariance portfolios. Further, the MVSK portfolios generally reduce allocations to the Event-Driven category of hedge funds. It has been shown that when assembling optimal fund-of-hedge-funds portfolios, a substantial reduction in risk from changes in the higher moments can be achieved with relatively little decrease in mean return. This paper concurs with previous studies of Feldman et al. ${ }^{16}$ and Davies et al. ${ }^{6}$ that Global Macro and Equity Market-Neutral strategies are key building blocks in fund-of-hedge-fund construction. From an asset allocation perspective, the MVSK optimisation indicates that hedge fund allocations should be lower than those suggested by the mean-variance framework.

\section{References and Notes}

1 Cvitani'c, J., Lazrak, A., Martellini, L. and Zapatero, F. (2002) 'Optimal Allocation to Hedge Funds: An Empirical Analysis', Quantitative Finance, Vol. 3, pp. 1-12.

2 Agarwal, V. and Naik, N. (2004) 'Risks and Portfolio Decisions Involving Hedge Funds', Review of Financial Studies, Vol. 17, No. 1, pp. 63-98.
3 Amenc, N. and Martellini, L. (2002) 'Portfolio Optimisation and Hedge Fund Style Allocation Decisions', Journal of Alternative Investments, Vol. 5, No. 2, pp. 7-20.

4 Amin, G. and Kat, H. (2003) 'Hedge Fund Performance 1990-2000. Do the "Money Machines" Really Add Value?', Journal of Financial and Quantitative Analysis, Vol. 38, No. 2, pp. 1-24.

5 Markowitz, H. (1952) 'Portfolio Selection', Journal of Finance, Vol. 7, No. 1, pp. 77-91.

6 Davies, R., Kat, H. and Lu, S. (2005) 'Fund of Hedge Funds Portfolio Selection: A Multiple Objective Approach', Discussion Paper, ISMA Centre, University of Reading.

7 Johnson, D., Macleod, N. and Thomas, C. (2002) 'Modeling the Return Structure of a Fund of Hedge Funds', AIMA Journal.

8 Athayde, G. and Flores, R. (2001) 'Finding a Maximum Skewness Portfolio - A General Solution to ThreeMoments Portfolio Choice', Journal of Economics, Dynamic and Control, Vol. 28, No. 7, pp. 1335-1352.

9 Sortino, F. and Price, L. (1994) 'Performance Measurement in a Downside Risk Framework', Journal of Investing, Vol. 3 (Fall), pp. 59-65.

10 Shadwick, W. and Keating, C. (2002) 'A Universal Performance Measure', Working Paper, Finance Development Centre, London.

11 Kazemi, H., Schneeweis, T. and Gupta, R. (2003) 'Omega as a Performance Measure', CISDM, University of Massachusetts.

12 Schneeweis, T., Spurgin, R. and Karavas, V. (2002) 'Alternative Investments in the Institutional Portfolio', Alternative Investment Management Association (AIMA).

13 Schneeweis, T. and Georgiev, G. (2002) 'The Benefits of Hedge Funds', CISDM, University of Massachusetts.

14 Lo, A. (2001) 'Risk Management for Hedge Funds: Introduction and Overview', Financial Analysts Journal, Vol. 57, No. 6, pp. 16-33.

15 Lhabitant, F. and Learned, M. (2002) 'Hedge Fund Diversification: How Much is Enough', Journal of Alternative Investments, Vol. 5, No. 3, pp. 23-49.

16 Feldman, B., Chen, P. and Goda, C. (2002) 'Portfolio with Hedge Funds', Working Paper, Ibbotson Associates.

17 Davies, R., Kat, H. and Lu, S. (2003) 'Higher Moment Portfolio Analysis with Hedge Funds', Discussion Paper, ISMA Centre, University of Reading.

18 This window of time includes the south-east Asian and Russian debt defaults of 1998 that coincides with the LTCM crisis. It also covers the technology bubble of the late 1990s, its subsequent collapse and the 11th September, 2001 tragedy. This is a meaningful period over which to evaluate hedge funds as various market cycles and events have occurred. 
19 Ineichen, A. (2000) 'In Search of Alpha', Investing in hedge funds, UBS Warburg.

20 Liang, B. (1999) 'On the Performance of Hedge Funds', Financial Analysts Journal, Vol. 55, pp. 72-85.

21 In a Dedicated Short-Bias portfolio, all short positions generate cash that in turn earns interest - this creates a positive drift to the performance of the portfolio.

22 It must be noted that the skewness $\left(Z_{3}\right)$ and kurtosis $\left(Z_{4}\right)$ formulae above correct minor errors in the original formulae applied by Davies et al. ${ }^{6}$ The authors contacted $\mathrm{Sa} \mathrm{Lu}$, a co-author of the Davies et al ${ }^{6}$ paper, and she confirmed the appropriateness of the formulae applied above. A further difference is that Davies et al solve for optimal fund-of-hedge-fund portfolios subject to a unity variance constraint.

23 Minimum average monthly return of all the series is -0.13 per cent from the Dedicated Short-Bias index.

24 Maximum average monthly return of all the series is 1.17 per cent from the Global Macro index.
25 LTCM was a hedge fund managed by ex-Salomon Brothers bond traders and Nobel laureates where the fund was highly leveraged and followed a strategy of being long high-yield debt and short sovereign treasuries. During the events of the Russian debt default and the Asian crisis of 1998 - the fund collapsed and was rescued by a group of Wall Street investment banks.

26 Minimum average monthly return of all the series is 0.34 per cent from the Lehman Brothers US Cash Composite and the maximum average monthly return of all the series is 0.89 per cent from the Hedge Fund Composite index.

27 The MSCI World Equity index has a monthly standard deviation of 4.16 per cent and monthly mean return of 0.54 per cent, while the MSCI World Sovereign Bond index has a monthly standard deviation of 1.91 per cent and monthly mean return of 0.52 per cent. 